\title{
PEKERJAAN RETAINING WALL PROYEK JALAN TOL DEPOK - ANTASARI, DEPOK - INDONESIA
}

\author{
Febri Triwahyu ${ }^{1}$, Habsyah Dwieka Mahrum ${ }^{2}$, Yuwono $^{3}$ \\ 1,2,3Politeknik Negeri Jakarta, Jurusan Teknik Sipil, Jl. Prof. DR. G.A. Siwabessy, \\ Kukusan, Kota Depok, Jawa Barat, 16424 \\ e-mail: febry3w@gmail.com, hafsahdwieka@gmail.com, yuwono_20@yahoo.co.id
}

\begin{abstract}
Implementation of construction method must be achieved in terms of cost, quality and time planned. The use of appropriate work methods is beneficial in the completion of construction. The implementation of the RW-3 Retaining Wall work on the Depok-Antasari Paket 1 Selatan Toll Road Project at Sta $6+020$ - $6+100$, Depok - West Java. Must choose the proper construction method because the project area is located close to traffic flow on public roads that can cause traffic disruptions; therefore, effective, and efficient time management is needed in its implementation. This final project aims to find out the process of carrying out the bored pile and retaining wall foundation work, which includes preparatory work, measurement/surveying work, drilling work, lean concrete work, reinforcement fabrication, installation of formwork, and casting. In carrying out its work, an analysis is made of labor productivity, tools, and materials that influence the time of work implementation. In addition, the other goal is to find out the obstacles that occur in the field and the solutions made in solving these obstacles. The implementation of all work went well according to plan because selecting a suitable method and anticipating obstacles that occur in the field.
\end{abstract}

Keywords: bored pile; constraints; productivity; retaining wall; work.

\begin{abstract}
ABSTRAK
Pelaksanaan pembangunan sebuah konstruksi, harus tercapai biaya, mutu dan waktu yang telah direncanakan. Penggunaan metode kerja yang tepat, sangat membantu dalam penyelesaian konstruksi, pelaksanaan pekerjaan Retaining Wall RW-3 pada Proyek Jalan Tol Depok-Antasari Paket 1 Selatan pada Sta 6+020 - 6+100, Depok - Jawa Barat. Harus memilih metode konstruksi yang tepat disebabkan area proyek yang terletak berdekatan dengan arus lalu lintas pada jalan umum yang dapat menyebabkan terganggunya lalu lintas, oleh karena itu dibutuhkan manajemen waktu yang efektif dan efisien dalam pelaksanaannya. Tujuan proyek akhir ini adalah untuk mengetahui proses pelaksanaan pekerjaan fondasi bored pile dan retaining wall yang meliputi pekerjaan persiapan, pekerjaan pengukuran/surveying, pekerjaan pengeboran, pekerjaan lean concrete, pabrikasi tulangan, pemasangan bekisting dan pengecoran. Dalam pelaksanaan pekerjaannya, dibuat analisis terhadap produktivitas tenaga kerja, alat dan bahan yang berpengaruh pada waktu pelaksanaan pekerjaan. Selain itu tujuan lainnya adalah untuk mengetahui kendala yang terjadi dilapangan serta solusi yang dilakukan dalam penyelesaian kendala tersebut. Hasilnya, pelaksanaan seluruh pekerjaan berjalan dengan baik sesuai dengan perencanaan disebabkan pemilihan metode yang baik serta antisipasi terhadap kendala-kendala yang terjadi dilapangan.
\end{abstract}

Kata kunci: bored pile; kendala; retaining wall; pekerjaan; produktivitas 


\section{PENDAHULUAN}

Tata Laksana Konstruksi merupakan suatu rangkaian pekerjaan dalam membangun konstruksi, agar konstruksi yang sedang dilaksanakan dapat memenuhi syarat biaya, mutu, dan waktu. Untuk memenuhi ketiga syarat diatas maka pelaksanaan harus melakukan tahapan yang sesuai dengan metode yang telah direncanakan.(PT. PP (persero) Tbk. 2003).

Terdapat banyak sekali lingkup pekerjaan pada konstruksi jalan tol, salah satunya yang menarik bagi penulis yaitu pekerjan retaining wall.

Pada lokasi pekerjaan retaining wall ini berdekatan dengan arus lalu lintas pada jalan umum yang dapat menyebabkan terganggunya lalu lintas, oleh karena itu dibutuhkan manajemen waktu yang efektif dan efisien dalam pelaksanaannya. Mengingat volume pekerjaan yang cukup besar dan pelaksanaan mobilisasi yang sulit dijangkau, maka pelaksanaan pekerjaan retaining wall ini dilakukan secara segmental dan bertahap.

Berdasarkan uraian diatas, penulis tertarik untuk membahas lebih jauh mengenai metode pelaksanaan pekerjaan retaining wall.

Permasalahan yang diangkat dalam proyek akhir ini adalah: "Bagaimana cara agar persiapan dan pelaksanaan pekerjaan retaining wall pada Proyek pembangunan Jalan Tol Depok-Antasari Paket 1 Selatan dapat berjalan sesuai perencanaan".

Tujuan penulisan proyek akhir ini adalah sebagai berikut:

1. Menjelaskan tahapan pelaksanaan pekerjaan retaining wall.

2. Menganalisis kebutuhan alat, bahan, pekerja dan waktu pelaksanaan pekerjaan retaining wall.
Dinding penahan tanah (Retaining wall) adalah suatu bangunan yang dibangun untuk mencegah keruntuhan tanah yang curam atau lereng yang dibangun di tempat di mana kemantapannya tidak dapat dijamin oleh lereng tanah itu sendiri, dipengaruhi oleh kondisi gambaran topografi tempat itu, bila dilakukan pekerjaan tanah seperti penanggulan atau pemotongan tanah. (Sudarmanto, 1996).

\section{METODE PENELITIAN}

Yang digunakan untuk mengumpulkan data dalam penulisan naskah tugas akhir ini, yaitu:

1. Metode Peninjauan Lapangan

2. Studi Kepustakaan/ Literatur

3. Wawancara

Berikut ini merupakan flowchart tahapan penulisan:

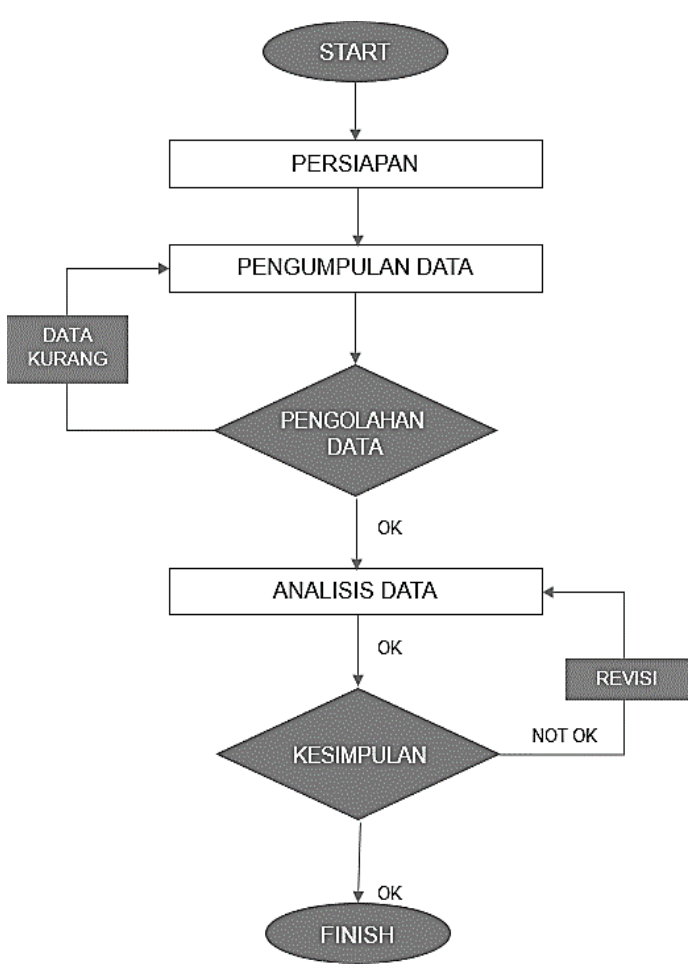

Gambar 1. Flowchart tahapan penulisan 


\section{HASIL dan PEMBAHASAN}

Berdasarkan pembahasan tentang pelaksanaan pekerjaan Retaining Wall RW-3 pada Proyek pembangunan Jalan Tol Depok-Antasari Paket 1 Selatan STA. 6+025 - 6+050 Depok - Jawa

Barat dapat diambil kesimpulan sebagai berikut :

1. Tahapan proses pelaksanaan pekerjaan Bored Pile dan Retaining Wall terdiri dari:

a. Pekerjaan Bored pile

Pada tahap pelaksanaan pekerjaan bored pile terdiri dari:
1). pekerjaan pengukuran, pekerjaan mobilisasi
2). pekerjaan pengeboran
3). Fabrikasi tulangan pekerjaan, kontrol mutu tulangan
4). pemasangan tulangan
5). pekerjaan pengecoran
6). kontrol mutu pengecoran
7). pelepasan casing.
Pada masing-masing pekerjaan telah dilakukan quality control sesuai dengan rencana.

b. Pekerjaan Retaining Wall

Pada tahap pelaksanaan pekerjaan

Retaining Wall terdiri dari:

1). pekerjaan pengukuran Footing

2). pekerjaan penggalian Footing

3). pekerjaan pembobokan bored pile

4). pekerjaan Lean Concrete

5). pemasangan tulangan Footing

6). pemasangan tulangan Dinding Wall

7). kontrol mutu tulangan

8). pemasangan bekisting Footing

9). pemasangan bekisting Dinding Wall

10). pekerjaan pengecoran Footing

11). pekerjaan pengecoran Dinding Wall

12). kontrol mutu pengecoran dan kemudian dilanjutkan

13). pekerjaan pembongkaran bekisting Footing dan Dinding Wall serta dilanjutkan dengan
14). curing selama 7 hari pada Footing dan 5 hari pada Dinding Wall. Pada masingmasing pekerjaan telah dilakukan quality control untuk mencapai hasil target yang diinginkan.

2. Hasil analisis kebutuhan bahan, alat, jumlah tenaga kerja yang dibutuhkan dalam pekerjaan Bored Pile dan Retaining Wall:

a. Dari hasil analisis kebutuhan bahan di setiap pekerjaan menunjukkan kesesuaian volume seperti yang direncanakan yaitu Bored pile dengan volume 91,95 m3, Retaining Wall dengan volume 204,747 m3 dengan memiliki mutu yang sesuai dengan standar yang ada dan berdasarkan pengamatan di lapangan supply sesuai dengan penjadwalan dan tidak terjadi keterlambatan.

b. Hasil analisis kebutuhan alat yang digunakan memiliki kapasitas yang sesuai dengan kebutuhan dan kondisi dilapangan, yaitu penggunaan 3 unit Truck mixer dengan 15 kali trip, 1 unit Concrete Pump, 1 unit Excavator 11 kali trip dan 1 unit Dumptruck dengan 3 kali trip. Alat yang digunakan juga memiliki kemampuan yang baik sehingga mendapatkan hasil kerja yang efektif dan sesuai dengan yang direncanakan.

c. Dari hasil analisis kebutuhan tenaga kerja pada setiap pekerjaan sesuai dengan yang

diperhitungkan yaitu dengan tenaga kerja 94 orang di pekerjaan Bored Pile dan Retaining Wall setiap waktu perencanaan serta memiliki keahlian yang baik.

d. Hasil analisis waktu pekerjaan dari observasi lapangan pada pekerjaan retaining wall sesuai dengan waktu yang telah direncanakan, namun pada pekerjaan pengeboran titik bored pile dan pembobokan kepala 
bored pile terjadi keterlambatan 3 hari dikarenakan terjadinya beberapa kendala dilapangan seperti longsornya lubang bor saat pengeboran dan kurang nya keahlian tenaga kerja. Maka dari itu unutk mengatasi hal tersebut adalah dengan ditambahnya waktu kerja.

\section{KESIMPULAN}

Dalam pelaksanaan pekerjaan Retaining Wall RW-3 dapat berjalan dengan lancar dan zero accident, kendala- kendala yang terjadi dapat di atasi dengan baik dan bijak. Berdasarkan hasil analisis, Pekerjaan retaining wall RW-3 ini dapat diselesaikan selama 35 hari kalender, lebih cepat 3 hari dari perencanaan proyek (master schedule) sebenarnya yaitu 38 hari kalender

\section{DAFTAR PUSTAKA}

[1] Sudarmanto, Konstruksi Beton 2, Jakarta, 1996
[2] PT. PP (persero), Tbk, Buku Referensi Untuk Kontraktor Bangunan Gedung dan Sipil, Jakarta: Gramedia, 2003.

[3] Departemen Pemukiman dan Prasarana Wilayah, (RSNI- T-122002) Tentang Pekerjaan Persiapan, Jakarta: Departemen Pemukiman dan Prasarana Wilayah, 2002.

[4] Badan Litbang Departemen Pekerjaan Umum, (SNI 2847-2013), Peraturan Beton Indonesia, Jakarta: Badan Litbang Departemen Pekerjaan Umum, 2013.

[5] Badan Standar Nasional, Baja Tulangan Beton, (SNI 07-20522002), Jakarta: Badan Standar Nasional, 2002.

[6] Badan Litbang Departemen Pekerjaan Umum, (SNI 91-00082007), Tata Cara Perhitungan Harga Satuan Pekerjaan Beton, Jakarta: Badan Litbang Departemen Pekerjaan Umum, 2012. 